American Journal of Applied Sciences 5 (8): 1083-1090, 2008

ISSN 1546-9239

(C) 2008 Science Publications

\title{
Simulink Model of Direct Torque Control of Induction Machine
}

\author{
H.F. Abdul Wahab and H. Sanusi \\ Faculty of Engineering, Universiti Kebangsaan Malaysia, 43600 UKM Bangi, \\ Selangor DE, Malaysia
}

\begin{abstract}
Direct torque control (DTC) is one of the most excellent control strategies of torque control in induction machine. It is considered as an alternative to the field oriented control (FOC) or vector control technique. These two control strategies are different on the operation principle but their objectives are the same. They aim to control effectively the torque and flux. Torque control of an induction machine based on DTC strategy has been developed and a comprehensive study is present in this research. The performance of this control method has been demonstrated by simulations performed using a versatile simulation package, Matlab/Simulink. Several numerical simulations have been carried out in a steady state and transient operation on a speed control mode.
\end{abstract}

Key words: Direct torque control, induction machine, vector control, Matlab/Simulink

\section{INTRODUCTION}

For many years, induction machine have provided the most common form of electromechanical drive for industrial, commercial and domestic applications that can operate at essentially constant speed. Induction machines have simpler and more rugged structure, higher maintainability and economy than DC motors ${ }^{[4]}$. They are also robust and immune to heavy loading. Basically, there are two types of instantaneous electromagnetic torque-controlled AC drives used for high performance applications which are:

- Vector Control (VC): based on stator current control in the field rotating reference using PWM inverter control.

- Direct Torque Control (DTC): based on stator flux control in the stator fixed reference frame using direct control of the inverter switching.

Direct torque control (DTC) has become an alternative to the well known Vector Control of induction machine. It was introduced in Japan by Takahashi (1984) and also in Germany by Depenbrock (1985). DTC of induction machine has increasingly become the best alternative to field orientation methods or vector control.

A block diagram of a DTC system for an induction machine is shown in Fig. 1, ${ }^{[2]}$. The DTC scheme is very simple; in its basic configuration it consists of hysteresis controllers, torque and flux estimator and a

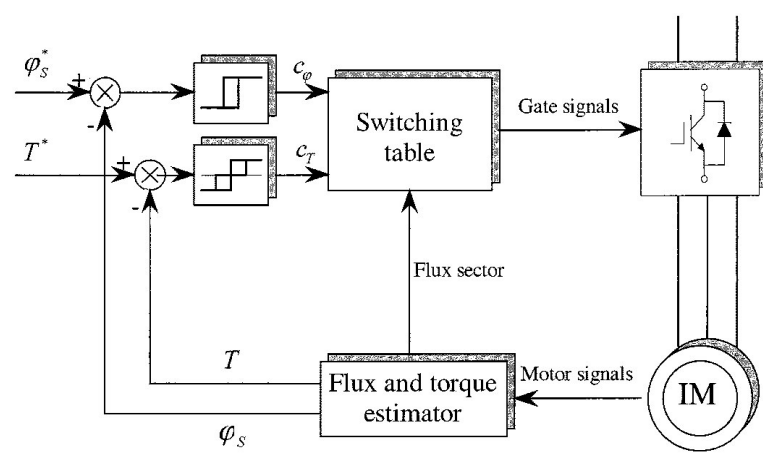

Fig. 1: Direct torque control of induction machine

switching table. The configuration is much simpler than the vector control system due to the absence of coordinate transformation between stationary frame and synchronous frame and PI regulators. It also does not need a pulse width modulator and a position encoder, which introduce delays and requires mechanical transducers respectively. DTC based drives are controlled in the manner of a closed loop system without using the current regulation loop ${ }^{[4]}$ DTC scheme uses a stationary $d-q$ reference frame (fixed to the stator) having its $d$-axis aligned with the stator $q$ axis. Torque and flux are controlled by the stator voltage space vector defined in this reference frame.

The basic concept of DTC is to control directly both the stator flux linkage (or rotor flux linkage, or magnetizing flux linkage) and electromagnetic torque of machine simultaneously by the selection of optimum

Corresponding Author: H. F. Abdul Wahab, Faculty of Engineering, Universiti Kebangsaan Malaysia, 43600 UKM Bangi, Selangor DE, Malaysia 
inverter switching modes. The use of a switching table for voltage vector selection provides fast torque response, low inverter switching frequency and low harmonic losses without the complex field orientation by restricting the flux and torque errors within respective flux and torque hysteresis bands with the optimum selection being made. The DTC controller consists of two hysteresis comparator (flux and torque) to select the switching voltage vector in order to maintain flux and torque between upper and lower limit.

The main objective of this paper is to develop the simulink model of direct torque control of induction machine based on the mathematical modelling.

\section{DTC DEVELOPMENT}

The develop torque control of inverter fed induction machine is carried out by hysteresis control of magnitude stator flux and torque that selects one of the six non-zero and two zero inverter voltage vectors shown in Fig. 2. The selection is made in order to maintain torque and flux error inside the hysteresis band in which the errors are indicated by $\Delta \mathrm{T}_{\mathrm{e}}$ and $\Delta \Psi_{\mathrm{s}}^{\mathrm{s}}$ respectively. Noting that

$$
\begin{aligned}
& \Delta \mathrm{T}_{\mathrm{e}}=\mathrm{T}_{\text {eref }}-\mathrm{T}_{\mathrm{e}} \\
& \Delta \psi_{\mathrm{s}}^{\mathrm{s}}=\bar{\psi}_{\text {sref }}^{\mathrm{s}}-\bar{\psi}_{\mathrm{s}}^{\mathrm{s}}
\end{aligned}
$$

The six different directions of $\bar{V}_{s}^{s}$ noted as $\bar{V}_{i}(i=1-6)$, considering $S_{a}, S_{b}$ and $S_{c}$ as the combination of switches status of the inverter are given by the expression:
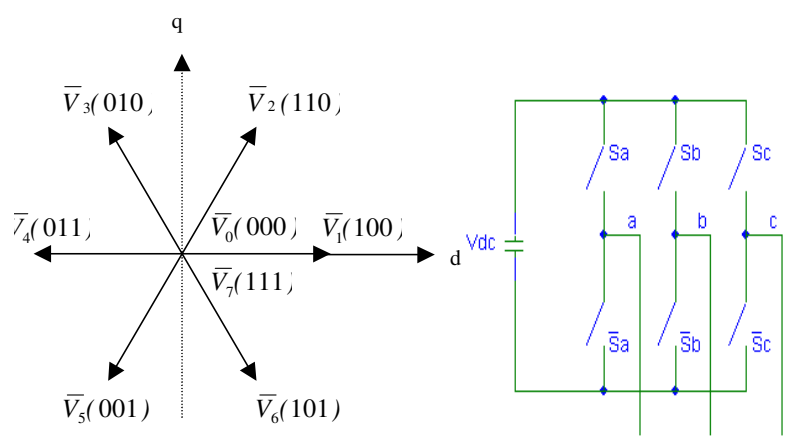

Fig. 2: Inverter output voltage vectors and voltage inverter

$$
\bar{V}_{\mathrm{s}}^{\mathrm{s}}=\frac{2 \mathrm{~V}_{\mathrm{dc}}}{3}\left(\mathrm{~S}_{\mathrm{a}}+\mathrm{e}^{\mathrm{j} 2 \pi / 3} \mathrm{~S}_{\mathrm{b}}+\mathrm{e}^{\mathrm{j} 4 \pi / 3} \mathrm{~S}_{\mathrm{c}}\right)
$$

Stator Flux Control: By selecting the appropriate inverter output voltage $\bar{V}_{i}$, the stator flux $\bar{\psi}_{s}^{s}$ rotates at the desired frequency $\omega_{\mathrm{s}}$ inside a specified band.

If the stator ohmic drops are neglected, the stator voltage impresses directly the stator flux in accordance with the equation as follow:

$$
\overline{\mathrm{V}}_{\mathrm{s}}^{\mathrm{s}}=\frac{\mathrm{d} \bar{\psi}_{\mathrm{s}}^{\mathrm{s}}}{\mathrm{dt}}
$$

or

$$
\mathrm{d} \bar{\psi}_{\mathrm{S}}^{\mathrm{s}}=\overline{\mathrm{V}}_{\mathrm{s}}^{\mathrm{s}} \mathrm{dt}
$$

Therefore the variation of the stator flux space vector due to the application of the stator voltage vector $\overline{\mathrm{V}}_{\mathrm{S}}^{\mathrm{s}}$ during a time interval of $\Delta \mathrm{t}$ can be approximated as:

$$
\Delta \bar{\psi}_{\mathrm{S}}^{\mathrm{S}}=\overline{\mathrm{V}}_{\mathrm{S}}^{\mathrm{S}} \Delta \mathrm{t}
$$

Torque Control: The electromagnetic torque given by equation (7) is a sinusoidal function of $\gamma$, the angle between $\bar{\psi}_{s}^{s}$ and $\bar{\psi}_{r}^{r}$ as shown in Fig. 3. Since the rotor flux changes slowly, the rapid variation of stator flux space vector will produce a variation in the developed torque because of the variation of the angle $\gamma$ between the two vectors:

$$
\mathrm{T}=\frac{\mathbf{3}}{\mathbf{2}} \mathrm{P} \overline{\mathrm{i}}_{\mathrm{s}} \bullet \mathrm{j} \bar{\psi}_{\mathrm{S}}
$$

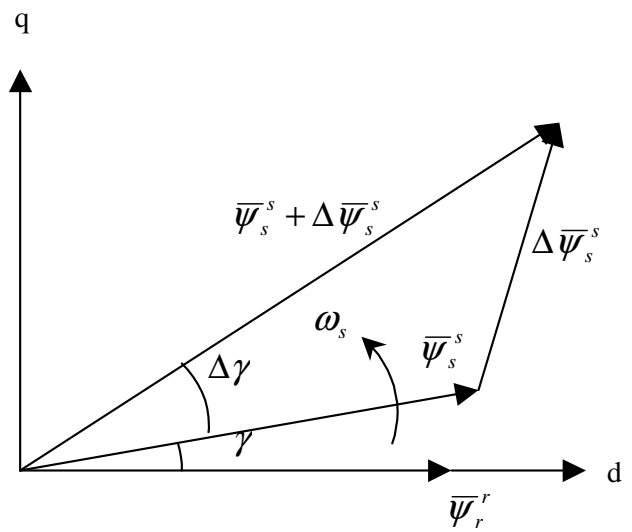

Fig. 3: Stator flux and rotor flux space vectors 


$$
\Delta \mathrm{T}_{\mathrm{e}}=\frac{3}{2} \cdot \frac{\mathrm{P}}{2} \cdot \frac{\mathrm{L}_{\mathrm{m}}}{\mathrm{L}_{\mathrm{s}} \mathrm{L}_{\mathrm{r}}-\mathrm{L}_{\mathrm{m}}^{2}}\left[\left(\bar{\psi}_{\mathrm{s}}^{\mathrm{s}}+\Delta \bar{\psi}_{\mathrm{s}}^{\mathrm{s}}\right) \bullet \mathrm{j} \bar{\psi}_{\mathrm{r}}^{\mathrm{r}}\right]
$$

Therefore to obtain a good dynamic performance, an appropriate inverter voltage vectors $\bar{V}_{i}$ has to be selected to obtain stronger rotation speed of $\omega_{\mathrm{s}}$.

The actual value of stator flux can be expressed as:

$$
\bar{\psi}_{\mathrm{s}}^{\mathrm{s}}=\int\left(\overline{\mathrm{V}}_{\mathrm{s}}^{\mathrm{s}}-\overline{\mathrm{i}}_{\mathrm{s}}^{\mathrm{s}} \mathrm{R}_{\mathrm{s}}\right) \mathrm{dt}
$$

where $\bar{V}_{s}^{s}$ and $\bar{i}_{s}^{s}$ indicate the measured stator voltage and current respectively.

The electromagnetic torque is calculated by means of equation (10):

$$
\mathrm{T}_{\mathrm{e}}=\frac{3}{2} \cdot \mathrm{P} \cdot\left(\psi_{\mathrm{ds}}^{\mathrm{s}} \mathrm{i}_{\mathrm{qs}}^{\mathrm{s}}-\psi_{\mathrm{qs}}^{\mathrm{s}} \mathrm{i}_{\mathrm{ds}}^{\mathrm{s}}\right)
$$

Switching Table: On the basis of the torque and flux hysteresis status and of the stator flux switching sector, which is denoted by $\alpha$, DTC algorithm selects the inverter voltage vector to apply to the induction machine from the Table 1. The outputs of the switching table are the settings for the switching devices of the inverter. Figure 4 shows the relation of inverter voltage vector and the stator flux switching sectors.

$$
\alpha=\angle \bar{\psi}_{\mathrm{s}}^{\mathrm{s}}=\tan ^{-1}\left(\frac{\psi_{\mathrm{qs}}^{\mathrm{s}}}{\psi_{\mathrm{ds}}^{\mathrm{s}}}\right)
$$

Active switching vectors: $\overline{\mathrm{V}}_{1}(100) ; \overline{\mathrm{V}}_{2}(110) ; \bar{V}_{3}(010)$; $\bar{V}_{4}(011) ; \bar{V}_{5}(001) ; \bar{V}_{6}(101)$

Zero switching vectors: $\bar{V}_{0}(000) ; \bar{V}_{7}(111)$

Table 1: Switching table of inverter voltage vectors

\begin{tabular}{llllllll}
\hline $\mathrm{d} \psi$ & $\mathrm{d} T_{e}$ & $\alpha(1)$ & $\alpha(2)$ & $\alpha(3)$ & $\alpha(4)$ & $\alpha(5)$ & $\alpha(6)$ \\
& & sector & sector & sector & sector & sector & sector \\
& & 1 & 2 & 3 & 4 & 5 & 6 \\
\hline 1 & 1 & $\overline{\mathrm{V}} 2$ & $\overline{\mathrm{V}} 3$ & $\overline{\mathrm{V}} 4$ & $\overline{\mathrm{V}} 5$ & $\overline{\mathrm{V}} 6$ & $\overline{\mathrm{V}} 1$ \\
& 0 & $\overline{\mathrm{V}} 7$ & $\overline{\mathrm{V}} 0$ & $\overline{\mathrm{V}} 7$ & $\overline{\mathrm{V}} 0$ & $\overline{\mathrm{V}} 7$ & $\overline{\mathrm{V}} 0$ \\
& -1 & $\overline{\mathrm{V}} 6$ & $\overline{\mathrm{V}} 1$ & $\overline{\mathrm{V}} 2$ & $\overline{\mathrm{V}} 3$ & $\overline{\mathrm{V}} 4$ & $\overline{\mathrm{V}} 5$ \\
0 & 1 & $\overline{\mathrm{V}} 3$ & $\overline{\mathrm{V}} 4$ & $\overline{\mathrm{V}} 5$ & $\overline{\mathrm{V}} 6$ & $\overline{\mathrm{V}} 1$ & $\overline{\mathrm{V}} 2$ \\
& 0 & $\overline{\mathrm{V}} 0$ & $\overline{\mathrm{V}} 7$ & $\overline{\mathrm{V}} 0$ & $\overline{\mathrm{V}} 7$ & $\overline{\mathrm{V}} 0$ & $\overline{\mathrm{V}} 7$ \\
& -1 & $\overline{\mathrm{V}} 5$ & $\overline{\mathrm{V}} 6$ & $\overline{\mathrm{V}} 1$ & $\overline{\mathrm{V}} 2$ & $\overline{\mathrm{V}} 3$ & $\overline{\mathrm{V}} 4$ \\
\hline
\end{tabular}

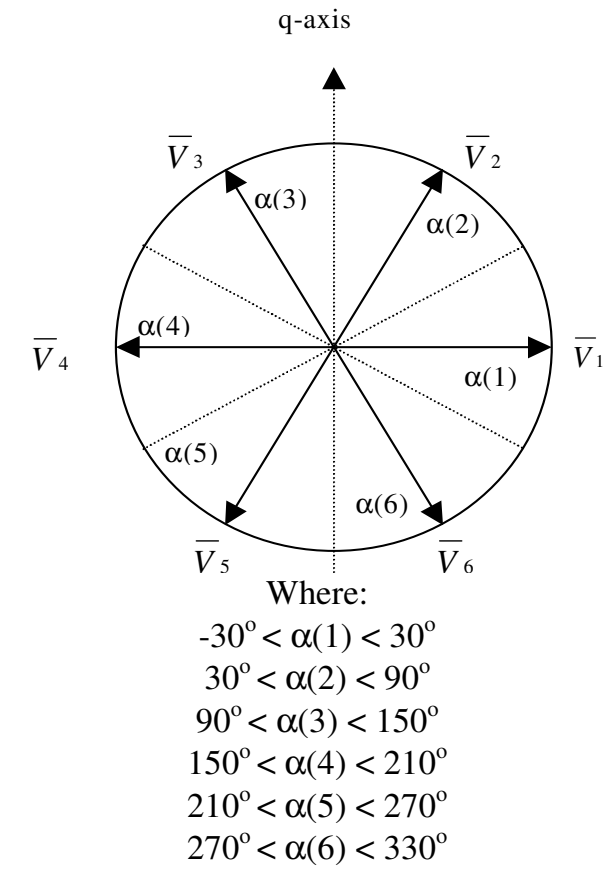

Fig. 4: Inverter voltage vectors and stator flux switching sector

\section{SIMULATION RESULTS AND DISCUSSIONS}

To study the performance of the developed DTC model, a closed loop torque control of the drive is simulated using Matlab/Simulink simulation package. The block diagram of the simulink model is shown in Fig. 5.

Start-up with No Load: Torque control dynamic performance of developed DTC model is evaluated by applying a step input of amplitude $30 \mathrm{Nm}$ after $0.4 \mathrm{~ms}$ to torque reference while the stator flux reference is maintained at $1 \mathrm{~Wb}$. The width of the hysteresis band is adjusted to $\pm 0.01 \mathrm{~Wb}$ for the flux comparator and \pm 0.01 $\mathrm{Nm}$ for the torque comparator. Maximum step size of $0.1 \mathrm{~ms}$ is used in this simulation. The obtained responses are shown in Fig. 6.

The equation of torque for no load running with single inertia and negligible friction is shown below:

$$
\mathrm{Te}=\mathrm{J} \frac{\mathrm{d} \omega \mathrm{r}}{\mathrm{dt}}
$$

From Fig. 6(a), the estimated electromagnetic torque remains at zero at period before $0.4 \mathrm{~ms}$, so the rotor does not rotate. At $\mathrm{t}=0.4 \mathrm{~ms}$, a step of $30 \mathrm{Nm}$ is 


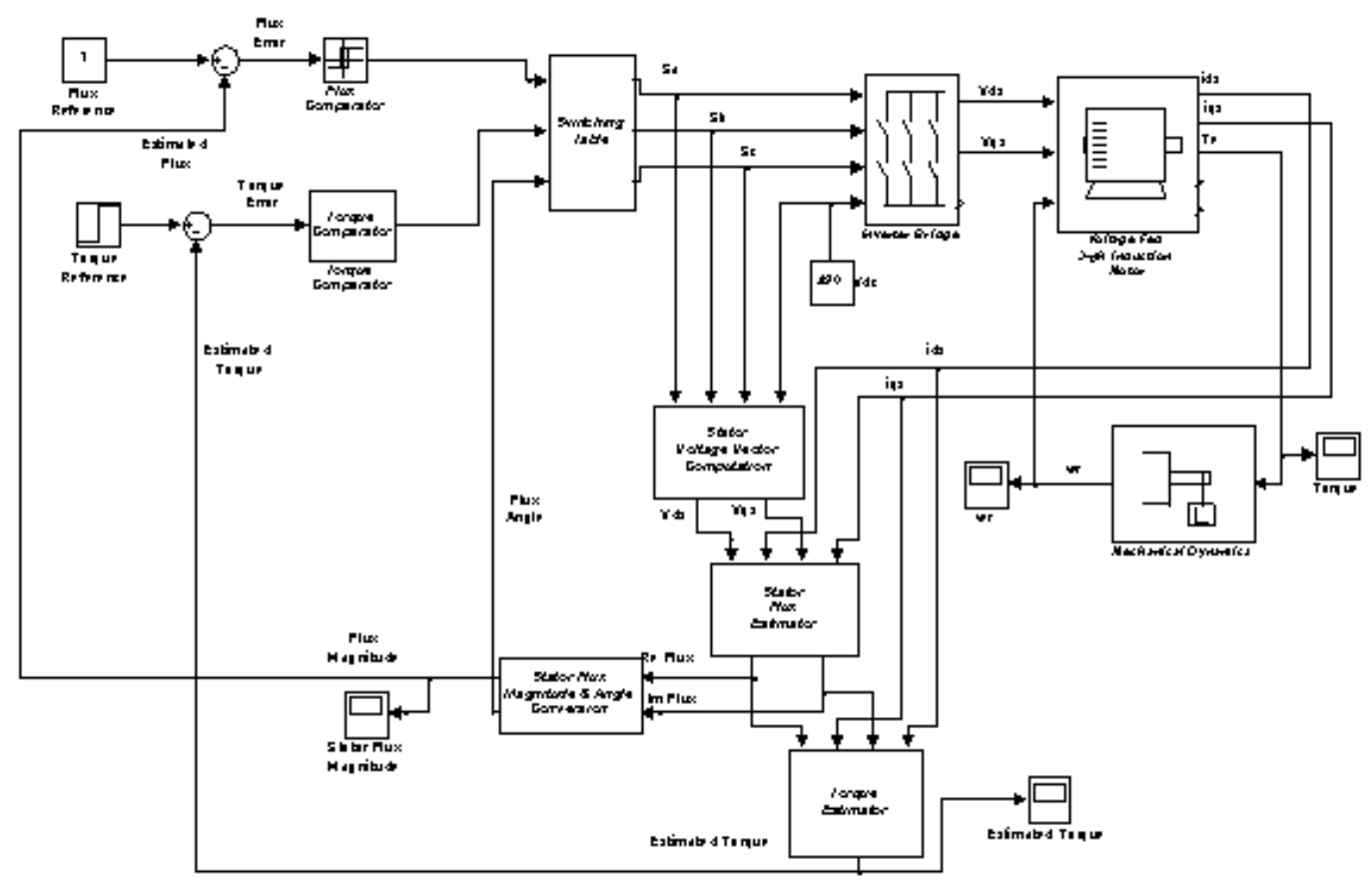

Fig. 5: Developed model of direct torque control of induction machine

applied to the torque reference and the electromagnetic torque immediately increases to reach the demand torque. This causes the rotor to accelerate at a rate dictated by the rotor inertia.

From the torque response, the acceleration is given by:

$$
\frac{\mathrm{d} \omega \mathrm{r}}{\mathrm{dt}}=\frac{\mathrm{Te}}{\mathrm{J}}=\frac{30}{0.05}=600 \mathrm{rad} / \mathrm{s}^{2}
$$

The rotor speed response in Fig. 6(b) behaves linearly during start-up. This is validating the equation of the speed for no load running with single inertia and negligible friction as below:

$$
\omega r=\int \frac{T e}{J} d t
$$

From the rotor speed response plot, the corresponding acceleration of the rotor speed can be calculated as below:

$$
\frac{\mathrm{d} \omega \mathrm{r}}{\mathrm{dt}}=\frac{\Delta \omega \mathrm{r}}{\Delta \mathrm{t}}=\frac{90-20}{0.2-0.08}=583.33 \mathrm{rad} / \mathrm{s}^{2}
$$

Both of the above acceleration calculations based on the estimated torque and the speed response are differ only by $2.8 \%$. Thus, the small difference in percentage can verify the accuracy of the developed model.

In this no load situation, the rotor speed would eventually accelerate to synchronous speed of 147.8 $\mathrm{rad} / \mathrm{s}$. There is $5.9 \%$ difference with the calculated of synchronous speed,

$\omega \mathrm{s}=\frac{2 \pi \times \mathrm{f}}{\mathrm{P}}=157.08 \mathrm{rad} / \mathrm{s}$. The response is shown in Fig. 7.

Figure 6(c) shows the stator flux magnitude response has risen to its final value of $1.0 \mathrm{~Wb}$ that is equal to the stator flux reference. The stator flux magnitude is also constrained within its hysteresis band of $\pm 0.01 \mathrm{~Wb}$ as shown in Fig. 6(d). The locus of the stator fluxes is presented in Figure 6(e). Since the stator flux magnitude is constantly maintained in the hysteresis band, the locus draws the figure of a circle.

In DTC scheme, a direct control of the stator current is not present and this may determine over current when a step variation of torque and flux are applied to the input command. Figure 6(f) and 6(g) show the stator current response. Due to the uncontrolled current during start-up, the machine exceeds the rated current with stator current amplitude, $\bar{i}_{s}^{s}>80 \mathrm{~A}$ as shown in Fig. $6(\mathrm{~g})$. It can be noted that 
Am. J. Applied Sci., 5 (8): 1083-1090, 2008

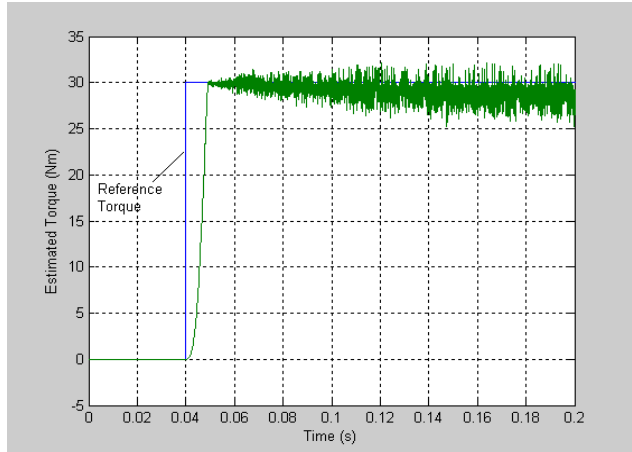

(a)Estimated torque

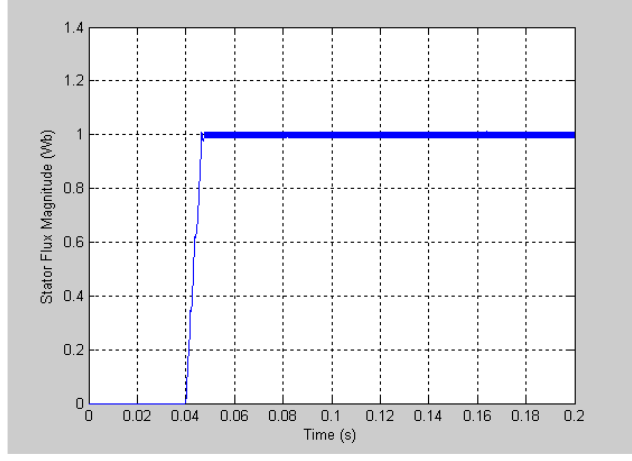

(c) Stator flux magnitude

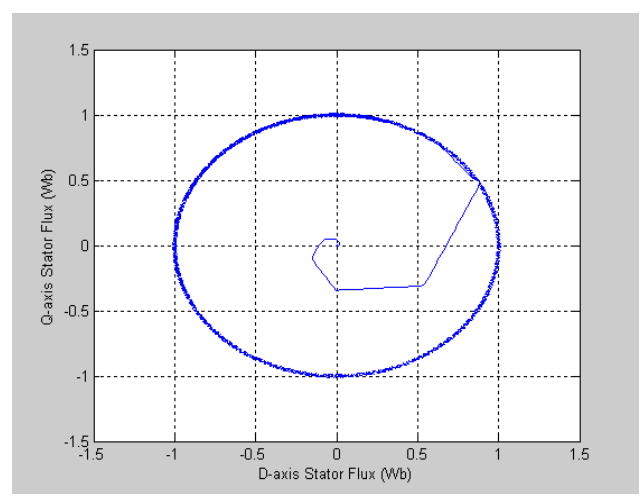

(e) Locus of the stator flux

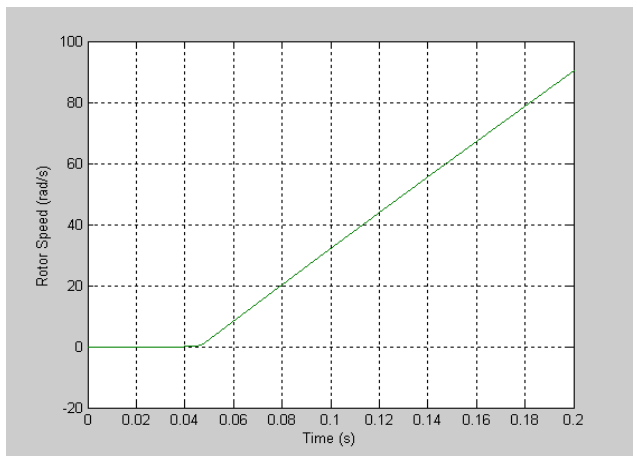

(b) Rotor speed

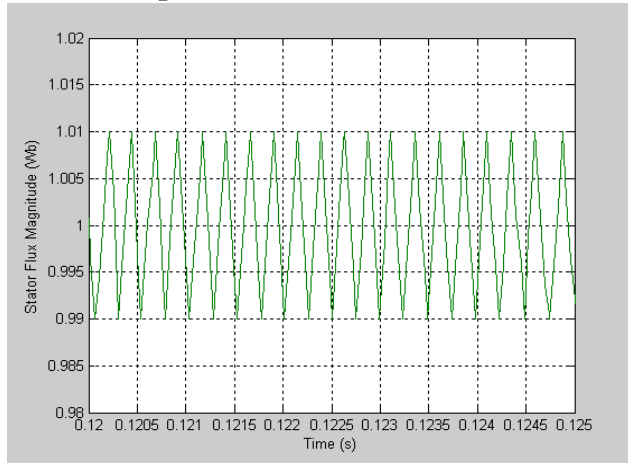

(d) Stator flux magnitude constrained in hysteresis band

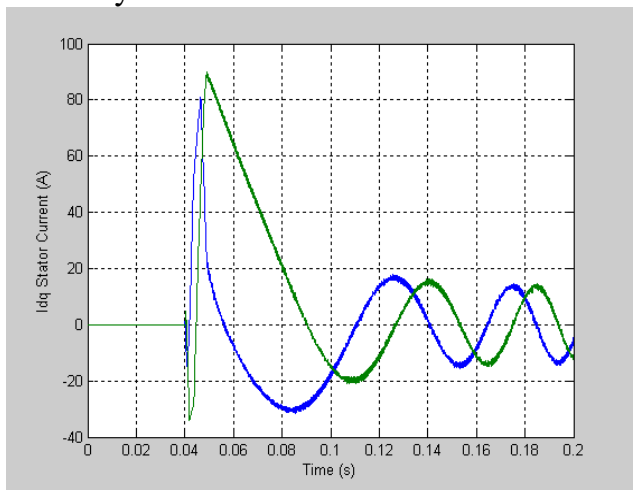

(f) D-axis and q-axis stator current

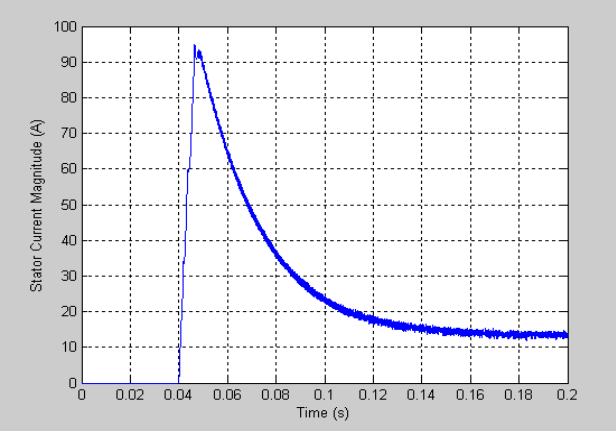

(G) Stator current

Fig. 6: a-g: DTC behaviour during start-up with no load 


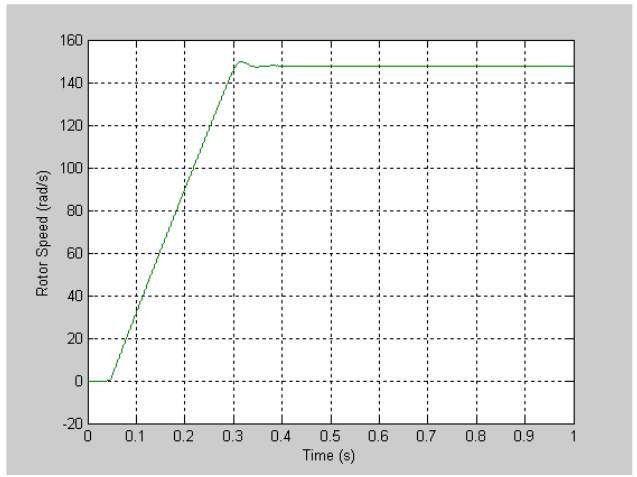

Fig. 7: Steady state response of rotor speed with no load

even a small variation of stator flux command as in Fig. 6(c), causes a large variation of the stator current. A control method to limit the current amplitude can be applied. ${ }^{[3]}$ has proposed to pre-flux the machine prior to apply the torque demand to limit the starting current transient in DTC in order to prevent the damage of the switch powers of inverter.

Dynamic Behaviour: The transient performance of the developed DTC model has been tested by applying a step load torque command from +20 to $-20 \mathrm{Nm}$ on the mechanical dynamics. The flux reference is maintained at $1.0 \mathrm{~Wb}$. Figure 8 shows the results obtained.

As seen in Fig. 8(a) and 8(b), the estimated electromagnetic torque shows a good response and the current waveform is almost sinusoidal immediately after the step command. This demonstrates that the developed DTC achieved high dynamic performance in response to changes in demand torque. However, there are some performance degradation with torque overshoot in the torque transient owing to the hysteresis controllers used.

Figure 8c shows the stator flux magnitude, emphasizing the decoupled action of torque and flux control. It is observed that the variation of motor torque does not influence fluxes. Thus, DTC system can assure independent flux and torque control.

Effect of Flux Hysteresis Band: The flux hysteresis band mainly affects the stator current distortion ${ }^{[1],[5]}$. Thus, for a fixed torque hysteresis band, the distortion increases with the flux hysteresis band. Some simulation results are shown for different values of the flux hysteresis band amplitude. Fig. 9 shows the observable fact from the developed model. If small flux hysteresis band amplitude of $\pm 0.01 \mathrm{~Wb}$ is applied, the stator flux vector locus approaches a circle and the

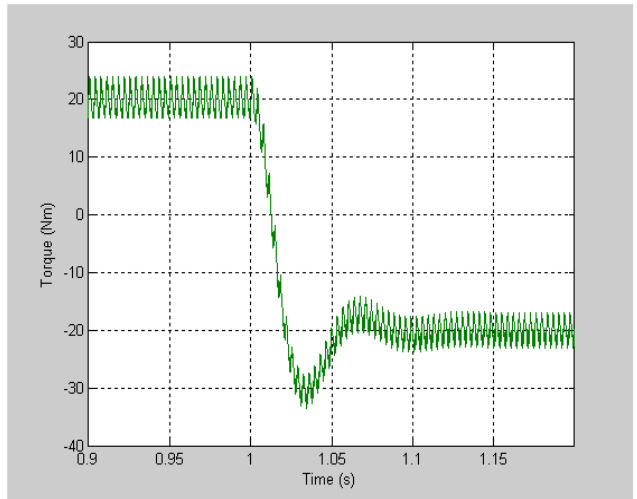

(a) Estimated torque

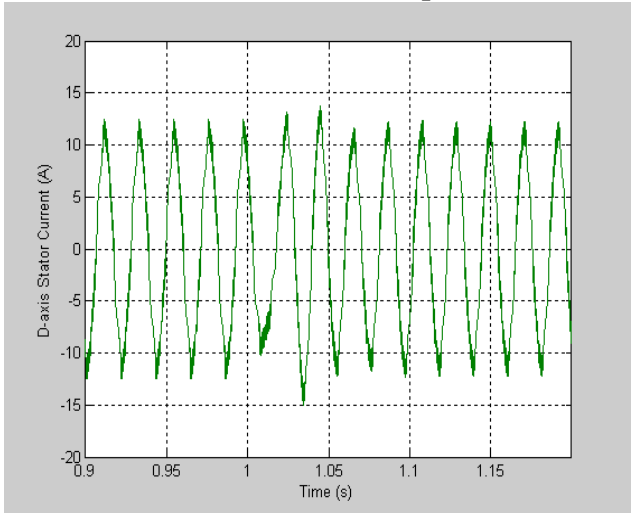

(b) D-axis stator current

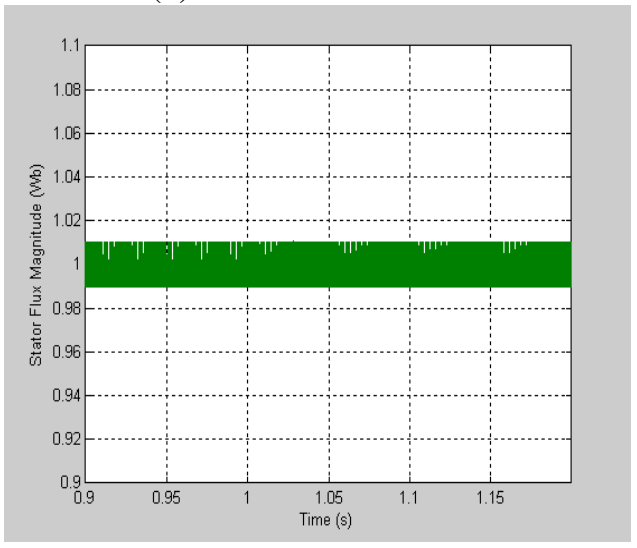

(c) Stator flux magnitude

Fig. 8: Dynamic behaviour of DTC during a load torque step command from $+20 \mathrm{Nm}$ to $-20 \mathrm{Nm}$

phase stator current waveform is sinusoidal. As the amplitude of the flux hysteresis band increases to \pm 0.1 $\mathrm{Wb}$, the stator flux locus approaches to a hexagon shape and the stator current distortion has also increased.

Effect of Torque Hysteresis Band: The selection of the width of the hysteresis band has important effects 

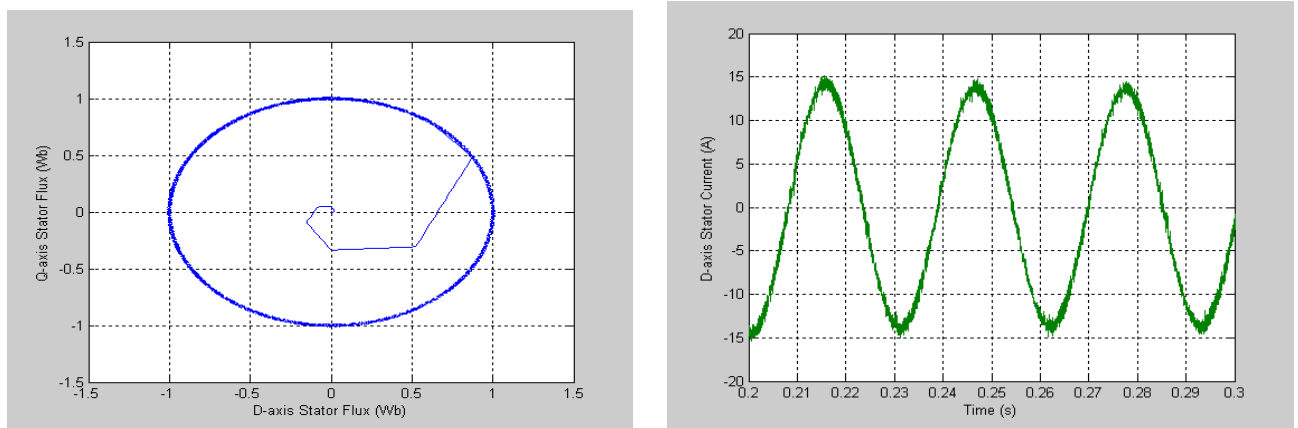

(a) Flux hysteresis band at $\pm 0.01 \mathrm{~Wb}$
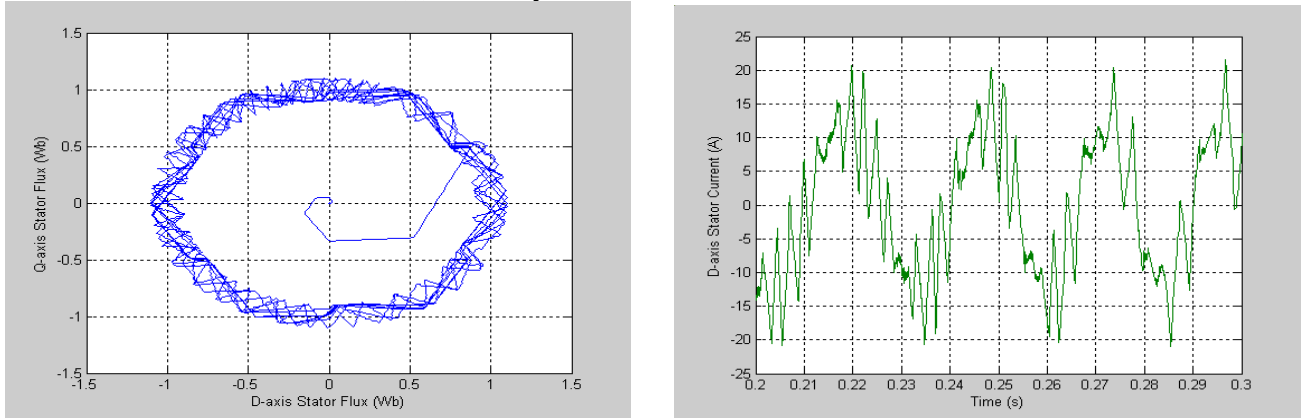

(b) Flux hysteresis band at $\pm 0.1 \mathrm{~Wb}$

Fig. 9: The effect of flux hysteresis band on the DTC performance

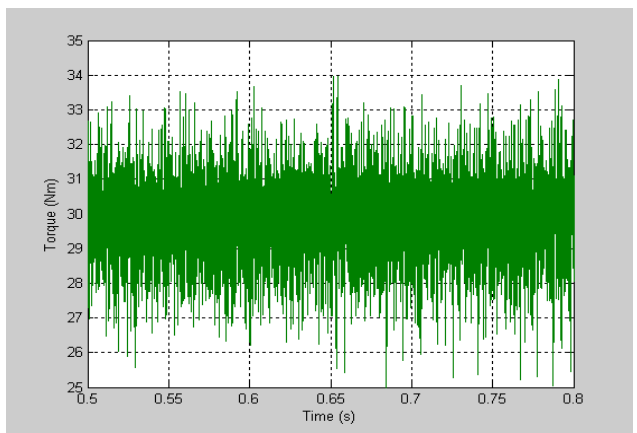

(a) Hysteresis Band $= \pm 0.01 \mathrm{Nm}$

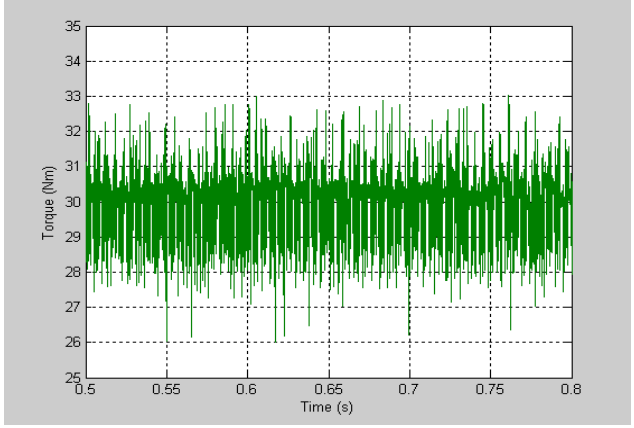

(b) Hysteresis band $= \pm 10 \mathrm{Nm}$

Fig.10: The effect of torque hysteresis band on the DTC performance switching frequency and thus the switching losses ${ }^{[1],[5]}$. If the band is too small, a torque overshoot may cause and it must be selected appropriately. It affects the the torque error to exceed the hysteresis band. This will result in a reverse voltage vector to be selected to reduce the torque. A reverse voltage vector will reduce the torque rapidly and hence may in turn causes a torque undershoots. Therefore, the torque ripple can become high if the torque hysteresis band is set too small. Figure 10 shows the effects of the torque hysteresis band.

\section{CONCLUSIONS}

The work carried out in this paper is aimed and focused to develop a direct torque control simulink model. The DTC architecture allows the independent and decoupled control of torque and stator flux. The implementation of the DTC model has been deeply described and justified its realization. In order to show the effectiveness of the model, a numerical simulation has been performed on a $7.5 \mathrm{~kW}$ induction machine fed by an IGBT PWM inverter. The feasibility and the validity of the developed DTC model, based on switching table technique, have been proved by simulation results obtained in the torque control mode. 


\section{ACKNOWLEDGEMENTS}

The authors would like to thank Professor J.W.Finch and Mr.Damion Giaouris for his guidance and valuable time.

\section{APPENDIX}

The test machine is a three phases and $50 \mathrm{~Hz}$ induction machine having the following parameters as shown in Table 2:

Table 2: Parameters of the tested induction machine

\begin{tabular}{ll}
\hline Power rating, $\mathrm{P}_{\text {rated }}$ & $7500 \mathrm{~W}$ \\
Rated voltage, $\mathrm{V}_{\text {rated }}$ & $400 \mathrm{~V}$ \\
Rated current, $\mathrm{I}_{\text {rated }}$ & $16 \mathrm{~A}$ \\
Pole pair, $\mathrm{P}$ & 2 \\
Stator resistance, $\mathrm{R}_{\mathrm{s}}$ & $0.6000 \Omega$ \\
Stator inductance, $\mathrm{L}_{\mathrm{s}}$ & $0.1230 \mathrm{H}$ \\
Rotor resistance, $\mathrm{R}_{\mathrm{r}}$ & $0.4000 \Omega$ \\
Rotor inductance, $\mathrm{L}_{\mathrm{r}}$ & $0.1274 \mathrm{H}$ \\
Magnetizing inductance, $\mathrm{L}_{\mathrm{m}}$ & $0.1200 \mathrm{H}$ \\
Inertia, J & $0.05 \mathrm{~kg} \mathrm{~m}^{-2}$ \\
\hline
\end{tabular}

\section{REFERENCES}

1. Casadei, D., G. Gandi, G. Serra and A. Tani, 1994. Effect of flux and torque hysteresis band amplitude in direct torque control of Induction Machine. Proc. IECON'94, Bologna, Italy, 299-304.

2. Casadei, D., F. Profumo, G. Serra and A. Tani, 2002. FOC and DTC: two viable schemes for induction motors torque control. IEEE Trans. Power Electronics, 17(5): 779-787.

3. Chapuis, Y.A. and D. Roye, 1998. Direct torque control and current limitation method in start up of an induction machine. IEE Conf. Power Electronics and Variable Speed Drives, 451-455

4. Takahashi, I. and Y. Ohmori, 1989. High Performace direct torque control of induction motor. IEEE Trans. Ind. Appl. 25 (2): 257-264.

5. Vas, P., 1990. Vector Control of a.c. machines.Oxford University Press. 